\title{
Laparoscopic Management of Strangulated Broad Ligament Hernia
}

\author{
Tanvi Khetan ${ }^{1}$, Abdulzahra Hussain ${ }^{2 *}$, Ihsan Al-Shoek ${ }^{3}$, Shamsi EL-Hasani ${ }^{4}$ \\ 'University College London, London, UK \\ ${ }^{2}$ General Surgery Department, Doncaster Royal Infirmary, Doncaster and Bassetlaw Teaching Hospitals, Doncaster, \\ UK \\ ${ }^{3}$ General Surgery Department, Frimley Park Hospitals, Surrey, UK \\ ${ }^{4}$ General Surgery Department, Kings College Hospitals, PRUH, London, UK
}

*Corresponding Author: Abdulzahra Hussain, M.D., General Surgery Department, Doncaster Royal Infirmary, Doncaster and Bassetlaw Teaching Hopsitals, Doncaster, DN2 5LT, UK. Tel: +44-1302636666, Email: azahrahussain@yahoo.com

Received January 6, 2018; Accepted March, 7, 2018; Online Published April 18, 2018

\begin{abstract}
Introduction: Broad ligament hernia was first reported post-autopsy by Quain in 1861. In a 1995 review article, only 61 cases had ever been reported. This paper presents a case report of broad ligament hernia and explores the literature surrounding this topic.

Case Presentation: The patient presented with no significant past medical history, acute lower abdominal pain (several hours), nausea, and vomiting. Clinical examination showed a heart rate of 85 beats per minute; normal temperature, blood pressure, and respiratory rate; and a mildly distended abdomen with tenderness across the right lower quadrant. A plain abdominal X-ray showed dilated small bowel loops, and a blood test showed leukocytosis. Urgent diagnostic laparoscopy showed a broad ligament strangulated hernia with small bowel infarction. Reduction of the small bowel, resection, and side-side anastomosis were performed. The patient had an uneventful recovery, and follow up reported no postoperative complications.

Conclusion: Laparoscopic management of small bowel obstruction due to broad ligament internal hernia is a safe and effective option.

Keywords: Laparoscopy, Broad Ligament, Hernia
\end{abstract}

\section{Introduction}

Internal hernias occur when there is a protrusion of the viscera through the peritoneum or mesentery within the peritoneal cavity. The most common type is paraduodenal hernia. ${ }^{1}$ Broad ligament hernias (BLH) make up $4 \%-5 \%$ of all internal hernias. Broad ligament (BL) defects still pose questions of how to diagnose and manage them. The first report of a broad ligament hernia was made post-autopsy by Quain in 1861, and a 1995 review article indicated only 61 cases have ever been reported. ${ }^{2}$ Defects have been broadly suggested to be congenital or acquired in origin. The typical patient in the literature was a middle-aged, multi-parous $(85 \%$ of cases) woman with no abdominal surgery. ${ }^{3} \mathrm{BLH}$ is one differential diagnosis of intestinal obstruction and those presenting with ileus.

$\mathrm{BLH}$ are generally difficult to diagnose because of their tendency to cause nonspecific symptoms such as nausea, vomiting, and abdominal pain. Therefore, these hernias are often found in exploratory laparotomy or diagnostic laparoscopy. In more recent years, diagnosis pre-surgically by computed tomography (CT) has been considered, as with $\mathrm{CT}$, it is possible to confirm the hernia's nature and location, obstruction, and type. ${ }^{4}$ However, more often than not, BLH are confirmed by surgical means. It has been suggested that a CT scan could be diagnostic when showing incarceration of a dilated intestinal loop in the Douglas pouch with air fluid levels. ${ }^{5}$ BL defects are usually found unilaterally and, if diagnosed pre-operatively with the absence of intestinal damage, they are often managed laparoscopically and have the benefits of minimal access surgery. The objective of this paper is to report the successful minimal access management of a BL strangulated hernia.

Copyright $($ C 2018 The Author(s). This is an open-access article distributed under the terms of the Creative Commons Attribution License (http:// creativecommons.org/licenses/by/4.0), which permits unrestricted use, distribution, and reproduction in any medium, provided the original work is properly cited. 


\section{Case Presentation}

A 35-year-old fit and healthy female presented with a history of 6 hours of acute lower abdominal pain, nausea, and vomiting. She had no significant past medical, surgical, or gynecological history. Clinical examination showed a heart rate of 85 beats per minute; normal temperature, blood pressure, and respiratory rate; a mildly distended abdomen with tenderness across the right lower quadrant; and normal examination of pelvic and hernial orifices. A plain abdominal X-ray showed dilated small bowel loops. Blood test showed leukocytosis (white blood cells were $\left.17000 \times 10^{9} / \mathrm{L}\right)$. Urgent diagnostic laparoscopy showed a broad ligament strangulated hernia with small bowel infarction. Reduction of the small bowel, resection of the infarcted segment of the terminal ileum, and side-side anastomosis using Endo GIA were performed (Figure 1). The enterotomy was closed in two layers using vicryl $2 / 0$ stitch, and the abdomen was drained. The patient had an uneventful recovery, and follow up at 2 and 8 months identified no postoperative complications.

\section{Discussion}

Urgent laparoscopy may be the preferred method over laparotomy to manage acute bowel obstruction with signs of strangulation in a virgin abdomen. ${ }^{6}$ A trial of conservative treatment is still a valid option when also considering the clinical picture and computed tomography (CT) findings. ${ }^{7}$ The causes for small bowel obstruction in a virgin abdomen are internal hernias, congenital bands, bowel tumors, Meckel's diverticulum, and luminal obstruction by bezoars or foreign bodies. ${ }^{8-10}$ Most of these are managed by surgery after variable periods of conservative treatment.

The most common mode of presentation for BLH consists of abdominal pain, particularly "colicky abdominal pain", ${ }^{11}$ and nausea and/or vomiting. Listing the full variety of presentations would be extensive, as throughout the literature symptoms such as distended abdomen, constipation, diarrhea, and headaches have all been mentioned. Blood tests and ultrasounds were initial tests in a pregnancy case. ${ }^{12}$ Over time, X-rays appear to have been replaced by CT scans for cases of BL herniation. Laparoscopy has also become a more common method of diagnosing BLH when a surgical approach is needed. ${ }^{13}$

In most early cases, diagnosis and surgical management decisions were made at the same time; in later years BLH were more commonly diagnosed through laparoscopy. This was further confirmed in a 2007 study, which highlighted that laparoscopy has shown positive results thus far and stressed that laparoscopy should be the first-line surgical management for patients. ${ }^{14}$ The defects in most cases were closed to prevent reoccurrences, and the herniating material was often resected with uneventful recoveries. Laparoscopic treatment has been argued in the majority of modern literature to provide the patient with greater postoperative comfort and shorter periods of hospitalization when compared to open surgery. ${ }^{4}$ Laparoscopy also allows for definitive diagnosis and immediate treatment of

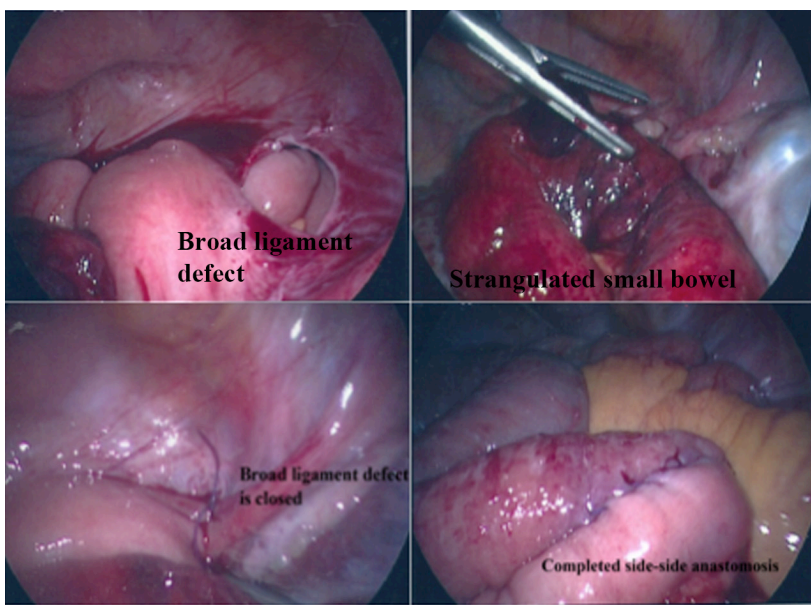

Figure 1. Laparoscopic View of the Defect, Infarcted Small Bowel, Closure of the Defect, and the Side-Side Anastomosis After Resection.

internal hernias. ${ }^{15}$

This case has highlighted the importance of early diagnosis and successful management of BL internal hernia using the minimal access approach. Gynecologists and surgeons should have a high index of suspicion for early diagnosis and management of BLH to avoid drastic morbidity.

\section{Conclusion}

Laparoscopic management of small bowel obstruction due to broad ligament internal hernia is a safe and effective option. The literature shows that surgical management is the only safe option in these patients.

\section{Authors' Contributions}

TK drafted the article and searched PubMed for relevant papers; AH performed the operation, reviewed the paper, and provided critical analysis; IAS contributed to the concept, helped with references, and approved the final version; SELH contributed to the operation, provided critical review of the paper, and approved the final version.

\section{Conflict of Interest Disclosures}

The authors declare no financial ties or any conflicts of interest in relation to this work.

\section{Ethical Approval}

The authors confirm that the patient involved in this case report gave her consent for this paper to be published. The images are laparoscopic views, and the patient's identity remains anonymous.

\section{References}

1. Martin LC, Merkle EM, Thompson WM. Review of internal hernias: radiographic and clinical findings. AJR Am J Roentgenol. 2006;186(3):703-717. doi:10.2214/ajr.05.0644.

2. Fafet P, Souiri M, Ould Said H, Mattei M, Godlewski G. [Internal hernia of the small intestine through a breach of the broad ligament, apropos of a case. Review of the literature]. J Chir (Paris). 1995;132(6-7):314-317. 
3. Langan RC, Holzman K, Coblentz M. Strangulated hernia through a defect in the broad ligament: a sheep in wolf's clothing. Hernia. 2012;16(4):481-483. doi:10.1007/s10029-010-0761-1.

4. Marraoui W, Petitcolin V, Bros S, Slim K, Garcier JM, Da Ines D. Internal hernia of the broad ligament: CT diagnosis for laparoscopic management. Diagn Interv Imaging. 2012;93(78):621-624. doi:10.1016/j.diii.2012.03.016.

5. Guillem P, Cordonnier C, Bounoua F, Adams P, Duval G. Small bowel incarceration in a broad ligament defect. Surg Endosc. 2003;17(1):161-162. doi:10.1007/s00464-002-4228-z.

6. Tavangari FR, Batech M, Collins JC, Tejirian T. Small bowel obstructions in a virgin abdomen: is an operation mandatory? Am Surg. 2016;82(10):1038-1042.

7. Beardsley C, Furtado R, Mosse C, et al. Small bowel obstruction in the virgin abdomen: the need for a mandatory laparotomy explored. Am J Surg. 2014;208(2):243-248. doi:10.1016/j. amjsurg.2013.09.034.

8. Ismael H, Ragoza Y, Cox S. Intestinal stenosis of Garre: A rare cause of small bowel obstruction in the virgin abdomen. Int J Surg Case Rep. 2016;25:156-160. doi:10.1016/j.ijscr.2016.06.005.

9. Nasri B, Calin M, Shah A, Gilchrist B. A rare cause of small bowel obstruction due to bezoar in a virgin abdomen. Int J Surg Case Rep. 2016;19:144-146. doi:10.1016/j.ijscr.2015.12.039.
10. Sankey RE, Maatouk M, Mahmood A, Raja M. Case Report: Jejunal gastrointestinal stromal tumour, a rare tumour, with a challenging diagnosis and a successful treatment. J Surg Case Rep. 2015;2015(5). doi:10.1093/jscr/rjv050.

11. Ooi S, Hong K. Small bowel obstruction caused by dried apple. Int J Surg Case Rep. 2015;10:154-157. doi:10.1016/j. ijscr.2015.03.038.

12. Agresta F, Michelet I, Candiotto E, Bedin N. Incarcerated internal hernia of the small intestine through a breach of the broad ligament: two cases and a literature review. JSLS. 2007;11(2):255257.

13. VoTM, Gyaneshwar R, Mayer C. Concurrent sigmoid volvulus and herniation through broad ligament defect during pregnancy: case report and literature review. J Obstet Gynaecol Res. 2008;34(4 Pt 2):658-662.doi:10.1111/j.1447-0756.2008.00903.x.

14. Matsunami M, Kusanagi H, Hayashi K, Yamada S, Kano N. Broad ligament hernia successfully treated by laparoscopy: Case report and review of literature. Asian J Endosc Surg. 2014;7(4):327-329. doi:10.1111/ases.12119.

15. Talebpour M, Habibi GR, Bandarian F. Laparoscopic management of an internal double omental hernia: a rare cause of intestinal obstruction. Hernia. 2005;9(2):195-197. doi:10.1007/s10029004-0288-4. 